\title{
Narrativa
}

\section{Federico BERTONI, Letteratura. Teorie, metodi,}

strumenti

\section{Enrico Fantini}

\section{OpenEdition}

\section{Journals}

\section{Edizione digitale}

URL: https://journals.openedition.org/narrativa/557

DOI: $10.4000 /$ narrativa. 557

ISSN: 2804-1224

\section{Editore}

Presses universitaires de Paris Nanterre

\section{Edizione cartacea}

Data di pubblicazione: 1 décembre 2018

Paginazione: 176-177

ISBN: 978-2-84016-325-1

ISSN: $1166-3243$

\section{Notizia bibliografica digitale}

Enrico Fantini, «Federico BERTon, Letteratura. Teorie, metodi, strumenti», Narrativa [Online], 40 | 2018, online dal 01 novembre 2021, consultato il 08 décembre 2021. URL: http://journals.openedition.org/ narrativa/557 ; DOI: https://doi.org/10.4000/narrativa.557

Questo documento è stato generato automaticamente il 8 décembre 2021.

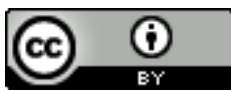

Narrativa est mise à disposition selon les termes de la Licence Creative Commons Attribution 4.0 International. 


\title{
Federico BERTONI, Letteratura. Teorie, metodi, strumenti
}

\author{
Enrico Fantini
}

\section{NOTIZIA}

Federico BERTONI, Letteratura. Teorie, metodi, strumenti, Roma, Carocci, 2018, 318 p.

1 In questo lavoro, Bertoni coniuga con equilibrio didattica e proposta critica. Vi riesce anzitutto ponendo lo studio della letteratura in "situazione", calandolo cioè nel suo presente di crisi e di marginalità (Che ci faccio qui?, pp. 13-19). L'attuale fase di incertezza rinnova la necessità di una riflessione sullo statuto della letteratura. L'accurata disamina di una serie di opposizioni fondamentali, che hanno strutturato per decenni la meditazione teorica (testualità versus contestualità, eteronomia versus autonomia, lingua comune versus elaborazione artisticamente connotata) approda a una proposta largamente "inclusiva" (p. 83), che media i vari oltranzismi: la letteratura si sostiene su di un giudizio di valore socialmente costituito, ma in ultima analisi esso è vincolato alla natura stessa dell'opera; è il prodotto del contesto ma non è risolvibile in esso; infine, la parola letteraria è al tempo stesso transitiva e intransitiva, trasparente e opaca, referenziale e autoreferenziale (p. 101). In questo modo la letteratura come istituzione diventa un campo di tensione tra soggetti, luoghi e categorie, tra regolamentazioni intrinseche ed estrinseche, che può permettersi di accogliere tanto, a seconda delle modulazioni storiche (Bob Dylan), ma non tutto (Gigi D'Alessio). Una proposta di realismo minimo, per dirla con Eco. Se qui giunge la sua definizione, perché però praticarla, fruirla o studiarla? Contro proposte utilitaristiche (o snobisticamente antiutilitaristiche), ma anche al di là di un approccio antropologico o cognitivo che non convince del tutto, Bertoni propone una definizione di letteratura giocata sui concetti di densità (o ambiguità semantica), complessità relazionale (il labirinto di nessi della struttura che fornisce foriero di sensi ulteriori) e contraddizione interna. Per usare le parole dell'autore, "l'aspetto più dinamico e vitale della letteratura sta proprio nella sua capacità di minare le nostre certezze, di frustrare il nostro bisogno di ordine e 
coerenza, di offrirci un'opportunità cognitiva in cui possiamo misurarci con l'errore, l'ambiguità, l'incoerenza, la contraddizione, la disarmonia, il conflitto" (p. 110). Per queste ragioni vale la pena studiarla: con quali mezzi però? Bertoni appronta una cassetta degli attrezzi - un prontuario in cui si forniscono una serie di strumenti utili all'analisi del testo letterario contro i cascami del senso comune (narratore, personaggio, genere, modo...) - scegliendo o adottando sempre le formule più flessibili e meno dogmatiche. Completano l'opera quattro ampie schede di lettura, parte integrante e arricchimento del testo: messa alla prova degli strumenti teorici illustrati nei capitoli "tecnici". Che i testi siano tutti capolavori (Underworld, Madame Bovary, Fuoco pallido, The Master of Ballantrae) non fa che rendere ancora più piacevole una lettura di per sé utile.

L'idea di teoria letteraria desumibile dal lavoro di Bertoni può essere espressa in questi termini: un insieme di protocolli stabili per "una migliore intelligenza del testo" (p. 285). Questa definizione minimale consente di reagire alla crisi che colpisce gli studi letterari salvandone le pratiche (da nebulizzare nel corpo sociale come l'Alka Seltzer di Enzensberger). E pazienza se ciò la trasforma in una tecnica flessibile e locale, adatta alla comprensione di questo testo più che del Testo (mathesis più singularis che universalis) e pazienza se la nebulizzazione è sinonimo di atomizzazione (con tanti saluti cioè alla classe degli specialisti, alla comunità scientifica). Al di là di questi aspetti, Letteratura è un libro che andrebbe inserito nel fuoco di un dibattito ampio in cui confrontarsi sulle questioni ultime circa la flessibilità della teoria come disciplina inclusiva e sulla definizione di letteratura come luogo dell'incertezza e dell'ambiguità. Viene da domandarsi ad esempio se, al pari di un gergo dell'autenticità (uno degli obiettivi polemici del lavoro), non si corra il rischio di scivolare a volte in un gergo dell'ambiguità; se la doppiezza e la complessità che per l'autore costituiscono i tratti essenziali della letteratura siano sempre di per sé positivi. 